\title{
SISTEMA INTERESTADUAL DE INSUMO-PRODUTO DO BRASIL: UMA APLICAÇÃO DO MÉTODO SUIT
}

\author{
Joaquim José Martins Guilhoto * \\ Carlos Alberto Gonçalves Junior ${ }^{+}$ \\ Jaqueline Coelho Visentin ${ }^{\ddagger}$ \\ DENISE IMORI $\S$ \\ Keyi Ando Ussami ${ }^{\text {II }}$
}

\begin{abstract}
Resumo
Este artigo propõe um método para a estimação de Tabelas de Produção e Uso Inter-regionais em condições de informação limitada denominado Supply and Use Interregional Tables - SUIT. O SUIT é aplicado na construção de um sistema para as 27 Unidades da Federação (UF) brasileiras para o ano de 2011. As principais características do SUIT são de: (i) poder ser diretamente aplicado a sistemas compostos por diferentes hierarquias regionais, (ii) ser consistente com as matrizes de insumo-produto nacionais e (iii) ser consistente com o sistema de contas regionais do IBGE. $\mathrm{O}$ artigo faz uma análise da estrutura produtiva, das relações interestaduais e dos fluxos de comércio entre as UFs.
\end{abstract}

Palavras-chave: insumo-produto; modelo inter-regional; Brasil.

\begin{abstract}
This paper proposes a method for the estimation of interregional supply and use tables in conditions of limited information called Supply and Use Interregional Tables - SUIT. The SUIT is applied in the estimation of a system for the 27 Brazilian Federation Units (FU) for the year 2011. The main characteristics of SUIT are: (i) it can be directly applied to systems composed of different regional hierarchies, (ii) it is consistent with national input-output matrices and (iii) it is consistent with the regional accounts system of Brazilian Statistical Office (IBGE). The paper makes analysis of the productive structure, the interstate relations and the trade flows among the FUs.
\end{abstract}

Keywords: input-output; interregional model; Brazil.

JEL classification: C67, D57, R15

DOI: http://dx.doi.org/10.11606/1980-5330/ea 139552

\footnotetext{
* Organização para Cooperação e Desenvolvimento Econômico (OCDE) e Universidade de São Paulo. E-mail: joaquim.guilhoto@oecd.org. O conteúdo desta publicação expressa a visão deste autor e não necessariamente representa a visão da OCDE ou dos seus países membros.

† Professor Adjunto no Departamento de Economia da Universidade Estadual do Oeste do Paraná (UNIOESTE). E-mail: carlosalbertojr@hotmail.com

‡ Universidade de São Paulo. E-mail: coelhovisentin@gmail.com

$\S$ DERSA - Desenvolvimento Rodoviário S/A. E-mail: denise.imori@dersa.sp.gov.br

II Universidade de São Paulo. E-mail: keyi.ussami@usp.br
} 


\section{Introdução}

O progresso econômico não ocorre ao mesmo tempo e em todas as partes de uma região. Existem forças que provocam a concentração espacial do crescimento em torno dos pontos onde ele se inicia. Isso faz com que regiões de um mesmo país apresentem disparidades econômicas bastante significativas (Hirschman 1977).

No caso do Brasil, a disparidade econômica entre as Unidades da Federação (UFs) é patente. Existem estados como o de São Paulo, que ocupa menos que $3 \%$ da extensão territorial brasileira e é responsável por $32 \%$ da produção do país, e estados como o do Pará, com 15\% do território nacional e que responde por pouco mais de $2 \%$ da produção ${ }^{1}$.

Além disso, de acordo com Hirschman (1977), o crescimento econômico pode ser transmitido entre as regiões. Isto é, uma vez que o crescimento se fortaleça em uma região, coloca em movimento forças que atuam nas partes restantes. Para o autor, o crescimento econômico de uma região causa uma série de repercussões, positivas ou negativas, nas demais regiões, a depender das relações de interdependência econômica estabelecidas entre elas.

Nesse cenário, dada a disparidade econômica entre os estados brasileiros e as suas diferentes estruturas produtivas, identificar como se estabelecem as relações econômicas interestaduais e como o crescimento de um estado pode afetar a economia das demais UFs é de suma importância. Essas informações podem auxiliar os gestores públicos a reduzir a desigualdade econômica regional, por exemplo.

A matriz insumo-produto nacional, por tratar todo o país como uma única região, não é capaz de captar como se dão as relações econômicas entre as UFs, principalmente no que diz respeito aos fluxos de comércio associados à estrutura produtiva e à Demanda Final entre os estados brasileiros.

Outrossim, é importante considerar que a construção de um sistema interregional de insumo-produto permite acessar as informações sobre as economias regionais, bem como torna possível a realização de análises de impactos e simulações de cenários em um recorte regional detalhado, tais como os empregados pelos estudos de Carvalho \& Perobelli (2009) e Perobelli et al. (2007).

Diante do exposto, o presente trabalho tem como objetivo apresentar o processo de construção de um sistema inter-regional de insumo-produto utilizando o método Supply and Use Interregional Tables - SUIT. Posteriormente, é realizada uma análise preliminar das relações interestaduais e da estrutura produtiva interestadual utilizando o sistema inter-regional estimado.

Não é objetivo do artigo discutir os vários conceitos de método. Para os fins aqui propostos, considera-se "método" como o conjunto de atividades sistemáticas e racionais que, com maior segurança e economia, permite alcançar o objetivo (Lakatos \& Marconi 2011). Além disso, para Kaplan (1969) o método deve permitir a compreensão do caminho seguido no processo de investigação, o que torna possível a outros cientistas retraçar os procedimentos daquele que alcança um resultado válido.

Desta forma, o SUIT combina, de forma sistemática, técnicas amplamente aplicadas na construção de sistemas inter-regionais de insumo-produto ${ }^{2}$ como:

\footnotetext{
${ }^{1}$ Dados do Instituto Nacional de Geografia e Estatística (IBGE) para o ano de 2012. Disponíveis em http: //Www.ibge.gov.br/estadosat/.

${ }^{2}$ Ver Miller \& Blair (2009).
} 
(i) Quocientes Locacionais; (ii) Quocientes Locacionais Interindústrias; e (iii) o método iterativo RAS. Isso permite que outros pesquisadores compreendam caminho percorrido e reproduzam, passo a passo, os procedimentos utilizados. Por isso, é denominado método SUIT.

Diferente de outros métodos, como o Interregional Input-Output Adjustment System - IIOAS apresentado em Haddad et al. (2017), o SUIT não utiliza matrizes de comércio construídas a partir da impedância comercial entre os pares origem-destino; isso dá maior flexibilidade ao SUIT na construção de sistemas compostos por diferentes hierarquias regionais (município - estado - país) $)^{3}$.

Além disso, o SUIT é construído combinando as abordagens bottom-up e top-down ${ }^{4}$. Dessa forma, ao mesmo tempo em que o método garante a consistência com as Matrizes Usos e Produção nacionais e com as Contas Regionais, também preserva as peculiaridades econômicas de cada região.

A partir da abordagem proposta, espera-se construir um sistema interregional que consiga captar as peculiaridades regionais da economia brasileira, de forma a auxiliar os gestores públicos na alocação eficiente de recursos escassos, com vistas à promoção do desenvolvimento das regiões. Além disso, procura-se contribuir para a discussão metodológica acerca da estimação de sistemas inter-regionais de insumo-produto em condições de informação limitada.

Para isso, o artigo está dividido em cinco seções. A primeira é dedicada a esta introdução. A segunda apresenta uma revisão bibliográfica sobre os métodos de estimação de sistemas inter-regionais de insumo-produto e destaca algumas das principais experiências nacionais e internacionais na estimação desses sistemas. A seção 3 apresenta a descrição do processo de estimação da matriz inter-regional de insumo-produto para os 27 estados brasileiros utilizando o método SUIT. A quarta seção é dedicada à demonstração de uma das possíveis aplicações da matriz inter-regional de insumo-produto estimada, e é seguida da seção 5, correspondente à conclusão.

\section{Análise insumo-produto regional}

Desde a década de 1950, diferentes modelos regionais de insumo-produto foram desenvolvidos, principalmente no intuito de capturar as peculiaridades e os padrões de interdependência regionais. Esses modelos podem ser classificados de acordo com os seguintes critérios: (i) número de regiões consideradas; (ii) reconhecimento (ou não) das ligações inter-regionais; (iii) grau de detalhamento implícito nos fluxos inter-regionais de comércio; e (iv) as hipóteses assumidas para estimar os coeficientes de comércio (Sargento 2009).

Os sistemas regionais de insumo-produto podem ser construídos com apenas uma região ou com duas ou mais regiões e suas interconexões. Para Isard et al. (1998), a vantagem dos modelos inter-regionais é considerar os transbordamentos (spillover effects), através dos quais podem se verificar as consequências do aumento na demanda de uma dada região sobre as demais regiões consideradas, bem como o feedback na própria região onde houve o incremento

\footnotetext{
${ }^{3}$ Os detalhes acerca dessa vantagem serão tratados na sessão em que são estimados os fluxos inter-regionais.

${ }^{4}$ Maiores informações sobre as abordagens top-down e bottom-up em Sanén \& Gamboa (2016) e Haddad (2009).
} 
inicial. A magnitude desses efeitos caracteriza o grau de interdependência econômica regional.

Para Leontief (1986), a interdependência econômica entre duas regiões ou entre dois setores da economia pode ser direta ou indireta. A interdependência é direta na medida em que os bens e serviços produzidos em uma região são absorvidos por setores produtivos ou pela demanda final (DF) de outra região. A interdependência indireta ocorre quando a ligação entre tais regiões ou indústrias é estabelecida por meio de setores produtivos de outras regiões, formando os chamados padrões triangulares ou multilaterais de comércio.

Para Isard et al. (1998), o maior foco geográfico dado à análise insumoproduto permite a incorporação de peculiaridades regionais e a concepção de estratégias ligadas ao planejamento urbano. Entretanto, a principal dificuldade para construção de sistemas regionais de insumo-produto é a insuficiência de informações, principalmente acerca dos fluxos comerciais intermediários entre os setores e as regiões.

O problema fundamental em um sistema insumo-produto de várias regiões é a estimação das transações entre as regiões. As matrizes de comércio inter-regional dificilmente estão disponíveis no nível de detalhamento necessário. Além disso, a necessidade de dados cresce exponencialmente com o número de regiões. Por exemplo, um sistema com 3 regiões possui 6 matrizes inter-regionais, já um sistema com 4 regiões possui 12 matrizes inter-regionais (Miller \& Blair 2009).

Para Round (1983), muito se avançou desde as primeiras incursões de Isard (1951) e Leontief et al. (1953) em extensões regionais de modelos insumoproduto. Porém, desde o início, a escassez de dados, bem como o alto custo para obtê-los através da coleta específica de dados primários, principalmente no que tange aos fluxos inter-regionais, têm sido os principais obstáculos para pesquisadores dessa área.

Diante da dificuldade de se obterem os dados necessários para construção dos sistemas insumo-produto com várias regiões a partir de dados censitários, os chamados "métodos não censitários" ganharam popularidade acadêmica (Round 1983).

Quando o sistema inter-regional é construído totalmente a partir de informações censitárias diretas, o método é classificado como "método com informação censitária". Por outro lado, quando as informações utilizadas para construir o sistema inter-regional são estimativas das informações diretas requeridas, o método é classificado como "método não censitário"5.

Para Round (1983), a utilização dos termos censitário e não censitário sugerem a existência de duas exclusivas e bem definidas técnicas de pesquisa. No entanto, na prática, as matrizes inter-regionais de insumo-produto são construídas de forma híbrida, combinando várias técnicas, de acordo com a quantidade de dados primários disponíveis.

No que tange aos métodos não censitários, a estimação das informações que não são diretamente conhecidas pode utilizar, entre outros instrumentos: (i) estimações baseadas em Quocientes Locacionais e suas variações; (ii) Modelos Gravitacionais; e (iii) Modelos Iterativos (RAS e suas variações). Contudo, de acordo com Montoya (1999), na prática, quando se desenvolve um sistema

\footnotetext{
${ }^{5}$ Essa classificação é baseada em Montoya (1999).
} 
inter-regional de insumo-produto, é comum a utilização combinada dessas e de outras formas de estimação ${ }^{6}$.

A construção de sistemas regionais e inter-regionais de insumo-produto é objeto de pesquisas nacionais e internacionais. Flegg et al. (2016) utilizam uma variação da técnica de Quociente Locacional para estimar uma matriz regional para a província de Córdoba na Argentina e comparam essa estimação com outros métodos disponíveis.

Riddington et al. (2006) fazem uma comparação entre os resultados obtidos pelo Método Gravitacional, o Quociente Locacional e os dados obtidos a partir de uma pesquisa realizada em uma região empresarial da Escócia. Por sua vez, Haddad et al. (2016) construíram um sistema insumo-produto inter-regional para a Colômbia com 33 regiões e sete setores, utilizando o Interregional Input-Output Adjustment System - IIOAS também sob condições de informação limitada.

No que diz respeito ao Brasil, vários esforços têm sido feitos nesse sentido. Entre eles podem-se destacar: (i) Guilhoto et al. (2010) construíram um sistema inter-regional de insumo-produto para os estados do Nordeste brasileiro; (ii) Domingues \& Haddad (2002) desenvolveram um sistema inter-regional para Minas Gerais e o restante do Brasil; (iii) Porsse et al. (2003) estimaram uma matriz inter-regional para o Rio Grande do Sul e o restante do Brasil; (iv) Ichihara et al. (2008) estimaram um sistema intermunicipal de insumoproduto para os municípios do estado de São Paulo; e (v) Guilhoto \& SessoFilho (2005a) construíram um sistema inter-regional para os nove estados de atuação do Banco da Amazônia e o restante do Brasil para o ano de 1999.

Os trabalhos anteriormente mencionados são estimações de sistemas interregionais municipais ou apenas para uma parte dos estados brasileiros. No que se refere à construção de um sistema inter-regional para todos os estados do Brasil, como é o caso do presente estudo, as iniciativas são escassas. Podemse mencionar Haddad et al. (2017) que utilizaram o método IIOAS para estimar um sistema inter-regional de insumo-produto para as 27 UFs brasileiras, com 68 setores e 128 produtos.

Barros \& Guilhoto (2014) também estimaram um sistema inter-regional de insumo-produto para 25 UFs para o ano de 1959 com 33 setores. Além disso, houve uma tentativa do Instituto de Pesquisa Econômica Aplicada (IPEA), que foi interrompida em 2013 sem a construção do sistema inter-regional ${ }^{7}$.

Após essa breve abordagem acerca das principais considerações no processo de construção de sistemas insumo-produto com mais de uma região, faz-se necessária a descrição detalhada do método proposto para a estimação do sistema interestadual brasileiro.

\section{Estimação da matriz inter-regional de insumo-produto para as 27 UFs do Brasil}

No Brasil, como em outros países do mundo, a restrição de informações para a construção de um sistema interestadual de insumo-produto é patente. Por

\footnotetext{
${ }^{6}$ Não é objetivo do presente trabalho descrever todas as técnicas não censitárias para a construção de sistemas inter-regionais. Veja, por exemplo: Roy \& Thill (2004), Riddington et al. (2006), além de Sargento (2009).

${ }^{7}$ Mais informações em: http://www.ipea.gov.br/redeipea/index.php? option=com_content\&vi ew=article\&id=98: matriz-insumo-produto-regional\&catid=89: projetos-de-pesquisa\&I temid=206
} 
isso, há necessidade da combinação de dados oficiais, provenientes das contas regionais e das pesquisas realizadas por órgãos como o Instituto Brasileiro de Geografia e Estatística - IBGE -, às técnicas não censitárias de estimação de sistemas inter-regionais de insumo-produto. Nesse contexto, o SUIT propõe uma técnica de estimação híbrida para a construção do modelo inter-regional para as 27 UFs do Brasil.

O ponto de partida é o sistema de insumo-produto nacional para o ano de 2011, desagregado em 68 setores e 128 produtos $^{8}$, obtido utilizando o método apresentado por Guilhoto \& Sesso-Filho (2005b) e Guilhoto \& SessoFilho (2010). Tal sistema tem como base as Matrizes de Usos e Produção e de Importação nacionais.

A Figura 1 apresenta o processo de construção do sistema inter-regional utilizando o SUIT, que será detalhado nas próximas seções.

\subsection{As Matrizes de Produção estaduais}

A Matriz de Produção Nacional informa o que cada indústria (setor) da economia produz de cada produto no país. O primeiro passo para a construção das Matrizes de Produção Regionais é a estimação dos Valores Brutos da Produção (VBPs) estaduais para os 68 setores e 128 produtos.

Para o atendimento desse objetivo, parte-se inicialmente das contas regionais para o ano de 2011 divulgadas pelo IBGE. Com base nas suas informações, obtém-se o total produzido por cada estado, o qual está desagregado em 18 setores econômicos. Em seguida, para desagregar as informações disponíveis para os 18 setores das economias regionais em 68 setores, conforme os dados disponíveis na Matriz de Produção Nacional estimada, utiliza-se a participação que cada estado tem na produção nacional de cada setor, proveniente das pesquisas oficiais realizadas pelo IBGE, tais como: (i) Pesquisa Industrial Anual 2011 (PIA); (ii) Pesquisa Pecuária Municipal 2011 (PPM); (iii) Pesquisa Agrícola Municipal 2011 (PAM); (iv) Pesquisa Anual de Serviços 2011 (PAS); (v) Pesquisa de Extração Vegetal e Silvicultura 2011 (IBGE-PEVS); (vi) Pesquisa Anual do Comércio 2011 (IBGE-PAC); (vii) Relação Anual de Informações Sociais 2011 (MTE-RAIS); (viii) Pesquisa Nacional por Amostra de Domicílios 2011 (PNAD); além de pesquisas setoriais tais como: (ix) Sumário Mineral 2011 do Departamento Nacional de Produção Mineral (DNPM); (x) Anuário Estatístico Brasileiro do Petróleo, Gás Natural e Biocombustíveis $2012^{9}$ da Agência Nacional de Petróleo (ANP); (xi) Sistema de Informações sobre Orçamentos Públicos em Saúde (SIOPS) ${ }^{10}$; (xii) ANS TabNet - Informações em Saúde Suplementar da Agência Nacional de Saúde Suplementar ${ }^{11}$; (xiii) Sistema de Informações sobre Orçamentos Públicos em Educação (SIOPE) do Fundo Nacional de Desenvolvimento da Educação (FNDE) ${ }^{12}$; e (xiv) InepData do Instituto Nacional de Estudos e Pesquisas Educacionais Anísio Teixeira $^{13}$.

\footnotetext{
${ }^{8} 68$ setores e 128 produtos correspondem ao maior nível de detalhamento dos dados das contas nacionais de 2011.

${ }^{9} \mathrm{O}$ Anuário 2012 consolida dados referentes ao período de 2002 a 2011.

${ }^{10}$ No momento em que o artigo foi escrito, encontravam-se disponíveis dados de 2002 a 2017.

${ }^{11}$ No momento em que o artigo foi escrito, encontravam-se disponíveis dados de 2000 a 2017.

${ }^{12}$ No momento em que o artigo foi escrito, encontravam-se disponíveis dados de 2005 a 2018.

${ }^{13}$ No momento em que o artigo foi escrito, encontravam-se disponíveis dados de 2007 a 2014.
} 
O VBP nacional por setor, obtido da Matriz de Produção Nacional, é então distribuído para as 27 UFs, utilizando-se as contas regionais e as pesquisas anteriormente citadas.

Inicialmente, as Matrizes de Produção das UFs mantêm a mesma estrutura da Matriz de Produção Nacional. Isto é, a produção de cada produto por cada setor nos estados segue a mesma proporção nacional. Para isso, são construídos os Coeficientes Nacionais de Produção $\left(C P_{s x p}^{n}\right)$, conforme a equação:

$$
C P_{s \times p}^{N}=M P_{s \times p}^{N} * \operatorname{inv}\left(\operatorname{diag}\left(\sum_{s=1}^{68} m p_{s p}\right)\right) \forall s=1, \ldots, 68 \text { e } p=1, \ldots, 128
$$

Em que:

- $s$ são os setores e $p$ os produtos;

- $M P_{\text {sxp }}^{N}$ é a Matriz de Produção Nacional;

- $m p_{s p}$ é cada elemento sp da Matriz de Produção Nacional.

Em seguida, os VPBs de cada setor em cada UF são multiplicados pelos $C P_{\text {sxp }}^{N}$ para a primeira estimativa das Matrizes de Produção Regionais $\left(M P_{s x p}^{U F}\right)$, conforme a equação:

$$
M P_{s \times p}^{U F}=\operatorname{diag}\left(V B P_{s}^{U F}\right) * C P_{s \times p}^{N} \forall s=1, \ldots, 68 \text { e } p=1, \ldots, 128
$$

em que:

- $V B P_{S}^{U F}$ são os VBPs setoriais de cada UF.

Posteriormente, utiliza-se o procedimento iterativo RAS ${ }^{14}$ para garantir a consistência entre as Matrizes de Produção Regionais, as contas regionais e a Matriz de Produção Nacional em quatro quesitos: (i) a soma da produção dos setores das matrizes regionais é a mesma da nacional; (ii) a soma da produção dos produtos das matrizes regionais é a mesma da nacional; (iii) a participação na produção nacional por setores de cada UF é consistente com a produção setorial de cada UF nas contas regionais, isto é, se o VBP setorial por UF for agregado em 18 setores, o resultado é equivalente ao das contas regionais ${ }^{15}$; (iv) a quantidade produzida de cada produto por cada setor nacionalmente $\left(m p_{i j}^{N}\right)$ é igual à soma da produção das 27 UFs do referido produto $\left(m p_{i j}^{U F}\right)$ por cada setor, isto é:

$$
m p_{s p}^{N}=\sum_{U F=1}^{27} m p_{s p}^{U F} \forall s=1, \ldots, 68 e p=1, \ldots, 128
$$

\footnotetext{
${ }^{14}$ Para maiores informações sobre o método RAS, ver Miller \& Blair (2009), Mínguez et al. (2009) e McDougall (1999).

${ }^{15}$ Como as contas regionais apresentam apenas a produção de cada UF por setor e não por produto, na construção das matrizes de produção regionais, garante-se a consistência com as contas regionais apenas por setor, dando mais liberdade à produção por produto entre as UFs.
} 
Figura 1: Descrição do processo de construção do sistema inter-regional para as 27 UFs brasileiras utilizando o método SUIT

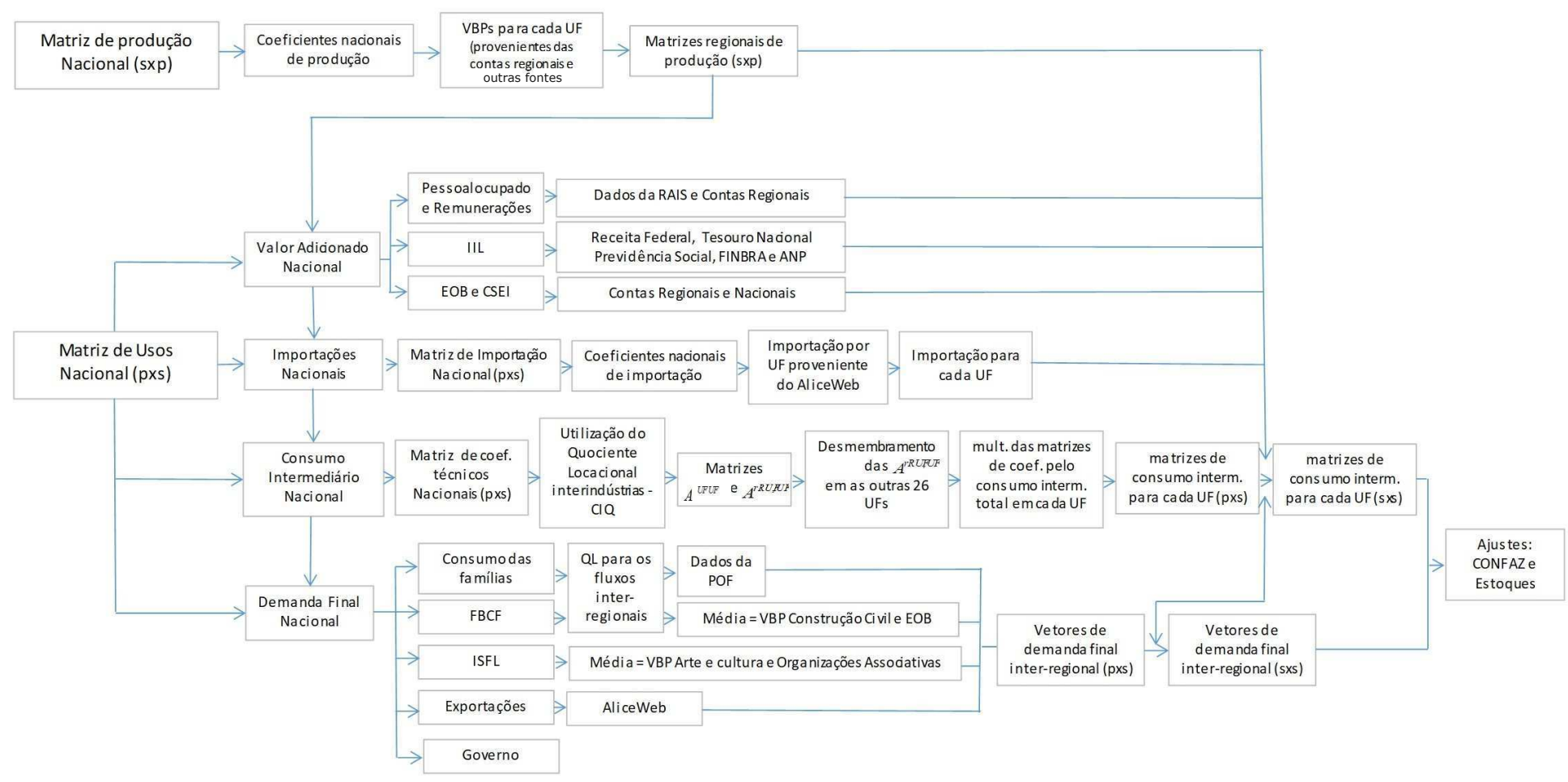

Fonte: elaborado pelos autores. 
Desse modo, obtém-se a Matriz de Produção (setor x produto) para cada UF nas dimensões 68 setores e 128 produtos. Além disso, esse procedimento altera a hipótese inicial segundo a qual as estruturas de produção regionais são as mesmas da estrutura nacional.

\subsection{As Matrizes de Usos para as 27 UFs}

O próximo passo é a construção das Matrizes de Usos (produto x setor) para as 27 UFs. As Matrizes de Usos são responsáveis por fornecer a quantidade de produtos que cada setor utiliza como insumo para realizar a sua produção. Para a descrição do processo de estimação de cada elemento dessas matrizes, utiliza-se como referência a Figura 2.

Figura 2: Elementos da Matriz de Usos (produto x setor) a ser construída para cada Unidade da Federação

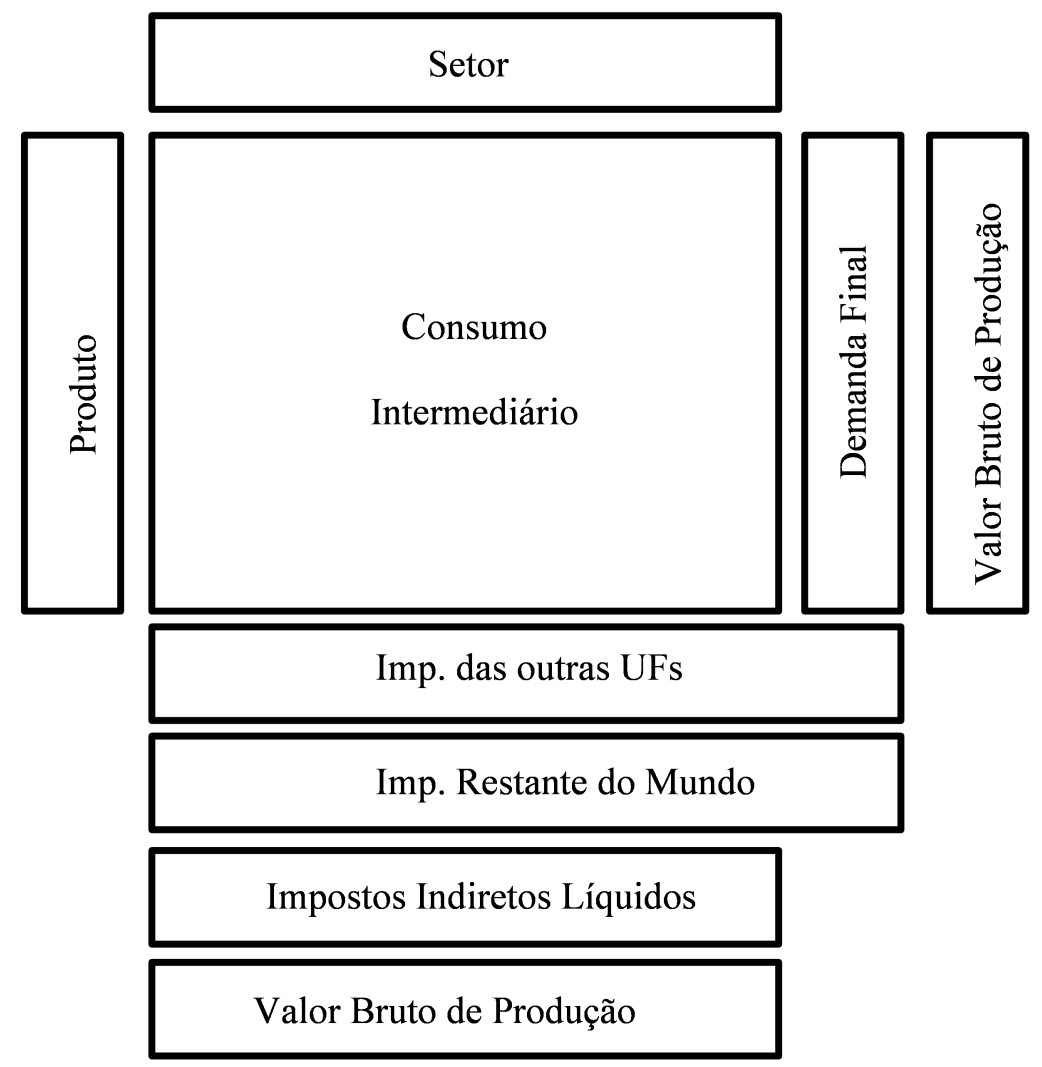

Fonte: elaborado pelos autores.

Os VBPs, por produto e por setor, já são conhecidos das Matrizes de Produção Regionais, anteriormente estimadas. As importações do restante do mundo compõem as Matrizes de Usos Regionais em um vetor linha, abaixo do consumo nacional. A participação de cada estado nas importações nacionais é obtida através do Sistema de Análise das Informações de Comércio Exterior $(\text { AliceWeb })^{16}$. Assim, com base nas participações de cada estado nas importa-

\footnotetext{
${ }^{16} \mathrm{O}$ referido sistema divulga as estatísticas brasileiras de exportação e importação e tem como
} 
ções nacionais, obtidas pelo AliceWeb, distribui-se o valor das importações, presente na Matriz de Usos Nacional, para cada UF. Para os produtos para os quais não existem informações disponíveis no AliceWeb, como é o caso de alguns serviços, utiliza-se a seguinte relação:

$$
m_{p}^{U F}=m_{p}^{N} \frac{Z_{p}^{U F}+d_{p}^{U F}}{Z_{p}^{N}+d_{p}^{N}}
$$

em que:

- $m_{p}^{U F}$ é a importação do produto $p$ na UF;

- $m_{p}^{N}$ é a importação nacional do produto $p$;

- $z_{p}^{U F}$ é a demanda intermediária do produto $p$ na UF;

- $z_{p}^{N}$ é a demanda intermediária do produto $p$ nacionalmente;

- $d_{p}^{U F}$ é a demanda final (DF) do produto $p$ na UF; e

- $d_{p}^{N}$ é a DF do produto $p$ nacionalmente (descontadas as exportações).

Essa relação, também utilizada por Többen \& Kronenberg (2015), considera que as importações regionais seguem a mesma proporção, em relação às importações nacionais, que a produção doméstica regional tem na produção doméstica nacional. A principal limitação é que essa equação não considera o fato de alguma UF ter aptidão maior/menor a importar um determinado produto que sua proporção (da UF) na produção nacional. No entanto, não se considera que isso seja um problema relevante, uma vez que, para os produtos com maior potencial de importação, os dados estão disponíveis no AliceWeb.

Pelo sistema AliceWeb, sabem-se quais produtos estão sendo importados por cada UF, porém, não se sabe quais setores das respectivas UFs estão importando, nem se essa importação é para Consumo Intermediário (CI) ou Demanda Final (DF).

Para solucionar esse problema, assume-se inicialmente que a utilização de produtos importados pelos setores de todas as UFs segue a mesma estrutura nacional, tanto para o CI quanto para a DF. Para isso, são construídos os Coeficientes Nacionais de Importação $\left(C i m p_{i x j}^{N}\right)$ utilizando-se a Matriz Nacional de Importações (produto x setor), construída pelo método Guilhoto \& SessoFilho (2005b) e Guilhoto \& Sesso-Filho (2010), conforme descrito a seguir.

$$
\operatorname{Cimp}_{p \times s}^{N}=\operatorname{inv}\left(\operatorname{diag}\left(\sum_{s=1}^{68} m i m p_{p s}\right)\right) * M i m p_{p \times s}^{N}
$$

em que:

- Mimp pxs é a Matriz Nacional de Importações;

base de dados o Sistema Integrado de Comércio Exterior (SISCOMEX), vinculado ao Ministério da Indústria, Comércio Exterior e Serviços (MDIC). É responsável ainda pela administração do comércio exterior brasileiro. Essa base de dados é gratuita e pode ser acessada pelo site http: / / aliceweb.desenvolvimento.gov.br/. 
- $\operatorname{mimp}_{p s}$ é cada elemento da referida matriz.

Em seguida, os coeficientes nacionais de importação são multiplicados pelas importações setoriais de cada UF $\left(i m p_{p x 1}^{U F}\right)$, as quais são obtidas no AliceWeb ou pela Equação (4).

$$
\left.\operatorname{Mimp} p_{p \times s}^{U F}=\operatorname{diag}\left(i m p_{p \times 1}^{U F}\right)\right) * C i m p_{p \times s}^{N}
$$

Dessa forma, obtém-se 27 matrizes de importações estaduais, as quais adotam a mesma estrutura nacional.

Em seguida, ajustam-se as Matrizes de Importações Regionais pelo método RAS garantindo que: (i) a participação de cada estado na importação de cada produto, obtida junto ao AliceWeb e à Equação (4), seja mantida; e (ii) a soma das importações de cada setor em cada UF seja a mesma da importação de cada setor nacionalmente.

Posteriormente, o vetor de importações setoriais que compõe a Matriz de Usos de cada UF é obtido de acordo com a seguinte multiplicação.

$$
V i m p_{1 \times s}^{U F}=e_{1 \times p}^{\prime} * M_{i m p}^{U F}
$$

em que:

- Vimp $p_{1 \times s}^{U F}$ é o vetor de importações setoriais para cada UF;

- $e_{1 \times p}^{\prime}$ é um vetor linha de elementos unitários.

Na matriz nacional, o Valor Adicionado (VA) é composto de: (i) Salários; (ii) Contribuições sociais efetivas e imputadas (CSEI); (iii) Impostos, líquidos de subsídios, sobre produtos; (iv) Outros impostos, líquidos de subsídios, sobre a produção; (v) Excedente Operacional Bruto (EOB); e (vi) Rendimento Misto Bruto (RMB).

Estima-se cada um dos componentes do VA por UF, de modo que posteriormente é realizada uma compatibilização dos resultados obtidos por meio do método RAS. Para isso, utilizam-se os dados do novo sistema de contas regionais do IBGE, o qual disponibiliza informações sobre o VA total por UF para 18 setores.

A referida estimação segue a seguinte estratégia: para o componente "Salários", utiliza-se a participação de cada UF na massa salarial do setor, disponível na RAIS/MTE, além de se empregarem adicionalmente os dados da PNAD; para o componente RMB, também são utilizados os dados da PNAD.

Para os demais componentes do VA, isto é, CSEI e EOB, assume-se a mesma estrutura da Matriz de Usos Nacional e ajusta-se pelo método RAS. Desse modo, procura-se garantir que: (i) a soma dos elementos (CSEI e EOB) setoriais na Matriz de Usos estimada para cada UF seja o mesmo das contas regionais; (ii) a proporção desses elementos no VA total do estado seja mantida a mesma das contas regionais; e (iii) a soma dos totais do CSEI e do EOB em cada UF seja igual ao total nacional. Desse modo, garante-se a consistência entre os componentes do VA na Matriz de Usos estimada para as UFs e as contas regionais. 
Os Impostos Indiretos Líquidos (IIL), tais como o Imposto de Importação, Imposto sobre Produtos Industrializados (IPI), Imposto sobre Circulação de Mercadorias e Serviços (ICMS) e outros impostos menos subsídios, também apresentados em um vetor linha, são obtidos para cada UF a partir de dados da Receita Federal, Tesouro Nacional, Previdência Social, Caixa Econômica Federal, Finanças do Brasil (FINBRA), Dados Contábeis dos Municípios (FINBRA) e Agência Nacional do Petróleo (ANP) (Royalties).

Todavia, como tais informações não são disponibilizadas para os 68 setores, utiliza-se a Matriz de Usos Nacional para proceder à desagregação desses dados. Assim, como a referida matriz apresenta o valor dos impostos por setor e também a produção total do referido setor para o Brasil, calcula-se a proporção entre o total de impostos arrecadados (por setor) e a produção total (por setor). Desse modo, a regionalização é feita aplicando essa proporção no IIL total arrecadado em cada estado, obtendo-se, assim, o IIL para cada um dos 68 setores.

Dessa forma, diante dos procedimentos descritos, é possível estimar: (i) os VBPs regionais; (ii) os elementos do VA; (iii) as importações do restante do mundo; e (iv) os IILs para cada UF, de modo que as seguintes condições devem ser respeitadas: o VBP nacional deve ser igual à soma dos VBPs das UFs; Importações + IIL + VA = Produto Interno Bruto (PIB) pela ótica da renda; e VBP - Importações - IIL - VA = somatório do CI, o qual se refere ao vetor linha correspondente à soma ao longo das colunas do CI de todos os setores.

Desse modo, todos os dados mencionados estabelecem uma correspondência entre o sistema inter-regional a ser estimado e o sistema de contas regionais. Os próximos passos são a estimação dos elementos da DF e do CI.

\section{Estimação dos elementos da Demanda Final}

A DF é composta por cinco elementos, além da Variação de Estoques, a saber: (i) exportações; (ii) consumo das famílias; (iii) consumo das Instituições sem Fins Lucrativos (ISFL); (iv) Formação Bruta de Capital Fixo (FBCF); e (v) gastos do Governo. Apresenta-se a seguir a metodologia empregada para a desagregação dos elementos da DF presentes na Matriz de Usos Nacional em informações regionais.

As informações sobre as Exportações são obtidas através do AliceWeb. No caso das exportações, não é necessário identificar o setor que adquiriu o produto no exterior. Dessa forma, a regionalização é feita pela aplicação das proporções da exportação de cada produto, obtidas junto ao AliceWeb, para cada UF, aos valores de exportações presentes na Matriz de Usos Nacional. Para os produtos cujos dados não estão disponíveis no AliceWeb, como é o caso de alguns serviços, utiliza-se a seguinte relação, também utilizada por Többen \& Kronenberg (2015):

$$
e_{p}^{U F}=e_{p}^{N} \frac{x_{p}^{U F}}{x_{p}^{N}}
$$

em que:

- $e_{p}^{U F}$ são as exportações regionais do produto $p$;

- $e_{p}^{N}$ são as exportações nacionais do produto $p$; 
- $x_{p}^{U F}$ e $x_{p}^{N}$ são, respectivamente, a produção bruta total regional e nacional.

O Consumo das Famílias, por UF e por produto, é auferido a partir da desagregação do Consumo das Famílias presente na Matriz de Usos Nacional. Para isso, utiliza-se a participação de cada UF no Consumo das Famílias de cada produto, de acordo com a Pesquisa de Orçamento Familiar (POF) 2008$2009^{17}$.

A desagregação do consumo das ISFL da Matriz de Usos Nacional em dados estaduais é feita por meio de uma média simples entre a participação de cada UF no VBP dos seguintes setores: (i) Arte, cultura, esporte e recreação e outras atividades de serviços (proveniente das contas regionais); e (ii) Organizações associativas e outros serviços pessoais (proveniente das Matrizes de Produção de cada UF, já estimadas).

A obtenção dos dados referentes à FBCF, por UF, tem o procedimento descrito: (i) faz-se a média simples entre a participação das UFs no VBP nacional da construção civil e no EOB nacional no intuito de obter, a partir da FBCF nacional, o total de FBCF para cada UF; (ii) em seguida, distribui-se o total de FBCF entres os setores das UFs utilizando a estrutura do vetor de EOB da respectiva UF anteriormente estimado; e (iii) torna-se necessário abrir o valor de FBCF de cada setor em cada UF nos 128 produtos, isto é, cada vetor linha de FBCF setorial das UFs precisa se tornar uma matriz (produto $\mathrm{x}$ setor). Para isso, utiliza-se a matriz de investimentos desenvolvida por Freitas (2016), conforme descrito a seguir.

$$
\begin{gathered}
C M i n v_{p \times s}^{N}=\operatorname{Minv} v_{p \times s}^{N} * \operatorname{inv}\left(\operatorname{diag}\left(\sum_{p=1}^{128} \operatorname{invest}_{p s}\right)\right) \\
F B C F_{p \times s}^{U F}=C M i n v_{p \times s}^{N} * \operatorname{diag}\left(f b c k_{1 \times s}^{U F}\right) \\
f b c f_{1 \times p}^{U F}=F B C F_{p \times s}^{U F} * e_{s \times 1}^{\prime}
\end{gathered}
$$

Em que:

- $M i n v_{p \times s}^{N}$ é a matriz de investimentos elaborada por Freitas (2016);

- invest $_{p s}$ é cada elemento da matriz de investimentos;

- $f b c k_{1 \times s}^{U F}$ é o vetor de FBCF setorial para cada UF;

- $f b c f_{1 \times p}^{U F}$ é o vetor de FBCF por produto que será inserido na Matriz de Usos de cada UF.

Em seguida, é preciso utilizar o RAS para garantir que: (i) a soma da FBCF de cada produto em todas as UFs seja igual ao total nacional da FBCF daquele produto; (ii) a soma da FBCF nas UFs seja o total da FBCF nacional; e (iii) a soma da FBCF dos produtos em cada UF seja o total de FBCF da UF.

\footnotetext{
${ }^{17}$ Esses são os anos de referência da POF mais recente disponível no momento em que este artigo foi escrito.
} 
Os Gastos do Governo das UFs são estimados com base na participação de cada UF no PIB da administração pública, divulgados pelo IBGE nas contas regionais. Por sua vez, essa participação é aplicada ao valor nacional dos Gastos do Governo, disponível na Matriz de Usos Nacional ${ }^{18}$.

\section{Estimação dos elementos do Consumo Intermediário}

O próximo elemento da Matriz de Usos a ser abordado é o CI (produto x setor). A hipótese inicial é de que a matriz de coeficientes técnicos diretos das UFs $\left(A^{U F}\right.$ para UF $\left.=1, \ldots, 27\right)$ é igual à matriz de coeficientes técnicos diretos nacional $\left(A^{N}\right)$. A partir dessa suposição, são utilizados os procedimentos descritos a seguir.

Primeiramente, calculam-se os fluxos intrarregionais, utilizando-se o método do Quociente Locacional Interindústrias ou Cross Industries Locational Quotient (CIQ).

O CIQ é uma variação do Quociente Locacional Simples. Essa variação permite diferentes modificações em uma dada linha da matriz nacional de coeficientes técnicos. Com essa técnica, é possível fazer ajustes célula por célula em $A^{N}$, em vez de empregar ajustes uniformes por toda a linha (como é o caso do Quociente Locacional Simples), conforme descrito a seguir.

$$
C I Q_{p s}^{U F, U F}=\frac{x_{p}^{U F} / x_{p}^{N}}{x_{s}^{U F} / x_{s}^{N}}
$$

em que:

- $x_{p}^{U F}$ e $x_{p}^{N}$ são os produtos totais regionais e nacionais do produto $p$, respectivamente;

- $x_{s}^{U F}$ e $x_{s}^{N}$ são os produtos regionais e nacionais do setor $s$, respectivamente.

A ideia básica é que, se a produção regional do produto $p$ relativo à produção nacional do produto $p$ é maior que a produção regional do setor $s$ relativo à produção nacional do setor $s$, isto é, $C I Q_{p s}^{U F}>1$, então todos os $s$ setores que precisam do insumo $p$ podem ser supridos dentro da região, caso contrário, o insumo precisa ser importado (Miller \& Blair 2009).

No entanto, o critério de ajuste do coeficiente nacional para o regional não é o mesmo para todos os produtos, pois é preciso considerar as características regionais e o potencial de comércio de cada produto, conforme a equação:

$$
a_{p s}^{U F, U F}=\left\{\begin{array}{ll}
\left(C I Q_{p s}^{U F}\right) \cdot\left(a_{p s}^{N}\right) & \text { se }\left(C I Q_{p s}^{U F}<X\right) \\
\left(a_{p s}^{N}\right) \cdot X & \text { se }\left(C I Q_{p s}^{U F} \geqslant X\right)
\end{array}\right\}
$$

Para os setores referentes a: (i) Agricultura; (ii) Extração Mineral; e (iii) Manufaturas, assume-se $X=0,95$. Para os setores de: (i) Administração Pública; (ii) Organizações Associativas e Serviços Pessoais; e (iii) Serviços Domésticos, assume-se que $\mathrm{X}=1$. Para os demais setores, $\mathrm{X}=0,9$.

\footnotetext{
${ }^{18}$ Além dos componentes anteriormente citados, a DF ainda apresenta a Variação de Estoques, mas esse componente será tratado posteriormente.
} 
Coeficientes intrarregionais menores permitirão maior comércio inter-regional. Por isso, a diferenciação no $\mathrm{X}$ é feita de modo a gerar maiores fluxos interregionais para os produtos que possuem maior potencial de comércio.

Após a estimação dos coeficientes intrarregionais para as $27 \mathrm{UFs}\left(A^{U F, U F}\right)$, calculam-se os fluxos inter-regionais. Primeiramente, estimam-se as matrizes de coeficientes técnicos correspondentes aos fluxos de cada UF com o restante das UFs (RUFs), ou restante do país, de acordo com a equação apresentada.

$$
A^{N}-A^{U F, U F}=A^{R U F, U F}
$$

em que:

- $A^{N}$ é a matriz nacional de coeficientes técnicos;

- $A^{U F, U F}$ é a matriz de coeficientes técnicos intrarregional para cada UF, já estimada;

- $A^{R U F, U F}$ é a matriz inter-regional que apresenta os coeficientes derivados do comércio do restante das UFs com cada UF.

Dessa forma, até agora, tem-se: (i) 27 matrizes intrarregionais, uma para cada UF; e (ii) 27 matrizes inter-regionais, relacionando o restante das UFs com cada UF. A próxima etapa é identificar a origem dos fluxos de compra de cada UF que compõem o agregado aqui chamado de "restante das UFs". Isto é, cada uma das 27 matrizes inter-regionais $A^{R U F, U F}$ será desagregada para cada uma das outras 26 UFs. Para isso, utiliza-se a equação:

$$
\operatorname{Partic}_{p}^{U F O \rightarrow U F D}=\frac{X_{p}^{U F O}}{X_{p}^{N}-X_{p}^{U F D}}
$$

Em que:

- $P a r t i c_{p}^{U F O \rightarrow U F D}$ é a participação da UF de origem nas compras da UF de destino;

- $X_{p}^{U F O}$ é a produção total do produto $p$ na UF de Origem;

- $X_{p}^{U F D}$ é a produção total do produto $p$ na UF de Destino;

- $X_{p}^{N}$ é a produção total nacional do produto $p$.

Exemplificando, se o estado de São Paulo compra soja do estado do Paraná e sabe-se que o Brasil, sem considerar São Paulo, produz 100 milhões de reais em soja e, destes 100 milhões, o Paraná responde por 30 milhões, então São Paulo irá comprar $30 \%$ da soja que utiliza do estado do Paraná. Obtida a matriz a inter-regional para cada uma das UFs, normalizam-se as mesmas pela coluna, de modo que a soma de cada uma das colunas seja igual a um.

Essa técnica é interessante pelo fato de considerar que a capacidade de produção de cada UF é essencial na determinação origem do fluxo, mesmo estando distante da UF de destino. A lógica está no fato de que, mesmo estando distante, um grande produtor pode oferecer um produto com maior qualidade, além disso, pode ter ganhos de escala que lhe permitam oferecer o 
produto a um melhor preço e compensar os custos de transporte e, com isso, manter sua proporção de vendas, mesmo nas UFs mais distantes.

Em trabalhos como Faria \& Haddad (2014) e Haddad et al. (2017), os fluxos de comércio são construídos baseados em modelos gravitacionais, que utilizam como referência a impedância comercial entre os pares origem-destino ${ }^{19}$ (por exemplo: a distância ou o tempo de viagem). No SUIT, os fluxos de comércio utilizam apenas as proporções da produção de cada produto em cada região na produção nacional do referido produto, conforme descrito na Equação (15).

Isso faz com que a aplicação SUIT seja facilitada, principalmente quando se deseja construir sistemas compostos por diferentes hierarquias regionais. Por exemplo, a construção de um sistema composto por um município, o restante dos municípios do estado e o restante do país. Quando se utiliza a impedância (distância ou tempo de viagem) entre os pares $\mathrm{O}-\mathrm{D}$, torna-se necessária a construção de matrizes de comércio para cada um dos municípios do estado, já que não existiria uma distância única entre o município isolado e uma região formada pelo restante dos municípios daquele estado, bem como do estado em relação ao restante do país.

Apesar da referida facilidade, quando comparados os resultados do SUIT e de sistemas que utilizam a impedância comercial, como o IIOAS, na construção de sistemas inter-regionais para as 27 UFs brasileiras, os resultados são bastante similares, conforme demonstrado em Gonçalves Jr \& Guilhoto (2018).

Os fluxos em valores monetários são obtidos pela multiplicação dessas matrizes pelo CI setorial de cada UF, conforme a seguinte apresentação.

$$
C I I_{p \times s}^{U F}=C I C I_{p \times s}^{U F} * \operatorname{diag}\left(C I T_{1 \times s}^{U F}\right)
$$

em que:

- $C I I_{p \times s}^{U F}$ é o CI inter-regional em valores monetários para cada UF;

- $C I C I_{p \times s}^{U F}$ é o coeficiente inter-regional de CI para cada UF;

- $C I T_{1 \times s}^{U F}$ é o CI total de cada setor em cada UF, que por sua vez é calculado de acordo com o procedimento descrito.

$$
C I T_{1 \times s}^{U F}=V B P_{1 \times s}^{U F}-V A_{1 \times s}^{U F}-I L L_{1 \times s}^{U F}-i m p o r t t_{1 \times s}^{U F}
$$

em que:

- $V B P_{1 \times s}^{U F}$ é o VBP para cada setor $s$ em cada UF;

- $V A_{1 \times s}^{U F}$ é o VA para cada setor $s$ em cada UF;

- $I L L_{1 \times S}^{U F}$ são os IIL;

- import $t_{1 \times s}^{U F}$ são as importações de cada setor em cada estado, ambos já estimados anteriormente.

\footnotetext{
${ }^{19}$ Essa técnica foi anteriormente aplicada por Dixon \& Rimmer (2004).
} 


\section{Estimação dos fluxos inter-regionais da Demanda Final}

No que diz respeito aos fluxos inter-regionais da DF, no método SUIT, assumese como hipótese a existência de fluxos apenas para o Consumo das Famílias e para a FBCF. O método não permite fluxos de comércio entre as UFs no que se refere: (i) às Exportações; (ii) ao Consumo do Governo; e (iii) ao consumo das ISFL.

De posse das estimativas anteriormente calculadas para o Consumo das Famílias e para a FBCF em cada estado e no país, utiliza-se o método do Quociente Locacional Simples para a estimação dos fluxos intrarregionais e interregionais desses elementos da DF.

Para isso, considere: (i) $x_{p}^{U F}$ podendo ser o valor do Consumo das Famílias ou a FBCF para cada produto $p$ na UF; (ii) $x^{U F}$ o total do Consumo das Famílias ou FBCF na UF; (3) $x_{p}^{N}$ o valor do Consumo das Famílias ou da FBCF para cada produto $p$ no país; e (4) $x^{N}$ o total do Consumo das Famílias ou FBCF no país. Assim, com base nessas considerações, o Quociente Locacional Simples $\left(Q L_{p}^{U F}\right)$ para o Consumo das Famílias ou para a FBCF na UF pode ser definido:

$$
Q L_{p}^{U F}=\frac{x_{p}^{U F} / x_{p}^{N}}{x^{U F} / x^{N}}
$$

O numerador reflete a proporção do Consumo das Famílias ou da FBCF para cada produto $p$ de uma determinada UF no Consumo das Famílias (ou FBCF) para cada produto $p$ nacional. Já o denominador expressa o quanto o total desses elementos da DF de cada UF representa em relação ao total dos referidos elementos na DF nacional. Logo, se $Q L_{p}^{U F}>1$, a concentração do consumo de $p$ na UF é maior do que no país.

O critério de decisão para a estimação do fluxo intrarregional, utilizando o Consumo das Famílias como exemplo, é:

$$
C F_{p s}^{U F, U F}=\left\{\begin{array}{ll}
\left(Q L_{p s}^{U F}\right) \cdot\left(C F_{p s}^{U F}\right) & \text { se }\left(Q L_{p s}^{U F}<X\right) \\
\left(C F_{p s}^{U F}\right) \cdot X & \text { se }\left(Q L_{p s}^{U F} \geq X\right)
\end{array}\right\}
$$

em que o valor de $X$ pode variar de acordo com o setor, seguindo os mesmos critérios do CI. No que diz respeito aos fluxos inter-regionais, repete-se exatamente o mesmo procedimento utilizado no CI, utilizando a Equação (15). Desse modo, obtém-se, então, todos os elementos necessários para a construção do sistema inter-regional.

Adicionalmente, é importante destacar que outro ajuste é feito no intuito de haver consistência entre a matriz estimada e os dados de comércio entre os estados, mensurados pelo Conselho Nacional de Política Fazendária (CONFAZ).

Para isso, ajustam-se os fluxos inter-regionais totais estimados aos divulgados pelo CONFAZ. Nas UFs onde o fluxo estimado pelo SUIT é maior do que o divulgado pelo CONFAZ, reduz-se a estimação realizada pelo SUIT. Por outro lado, nos casos onde o fluxo estimado pelo SUIT for menor do que o do CONFAZ, aumenta-se o respectivo valor em outras UFs.

No entanto, esse ajuste pode apresentar um limite. Em alguns casos, onde os valores estimados pelo SUIT se apresentaram muito maiores do que aqueles divulgados pelo CONFAZ para uma determinada UF, tal diferença não 
poderá ser totalmente compensada pela redução do referido fluxo em outras UFs quando isso gerar valores negativos para esses fluxos.

Os dados do CONFAZ não são ideais, já que não possuem a mesma desagregação setorial do sistema estimado, nem consideram os fluxos de serviços. No entanto, é a única publicação de fluxos de comércio entre as UFs disponibilizada por fontes oficiais.

Por fim, a Variação de Estoques é obtida por resíduo. Contudo, podem ser necessários alguns ajustes nessa diferença, pois alguns valores podem ser muito altos, tanto positivos como negativos. Alguns dos critérios de ajuste são:

(i) se na matriz nacional a variação de estoques é zero para um dado setor, então, na matriz inter-regional estimada esse mesmo elemento deve ser zero para todos os estados. Nesse caso, se houver algum saldo nessa conta, ele deve ser redistribuído ao longo da linha do CI e da DF;

(ii) é tolerada uma diferença entre a Variação de Estoque da matriz nacional e a de cada UF de $20 \%$. Os valores que excederem essa margem de tolerância são distribuídos ao longo da linha do CI. Para manter a matriz balanceada, o valor aumentado (reduzido) ao longo da linha é aumentado (reduzido) no mesmo setor para outro estado onde a tolerância também foi excedida, mas com sinal contrário.

Os procedimentos anteriormente descritos preservam a consistência do sistema inter-regional estimado pelo SUIT com as matrizes nacionais e as contas regionais. Os ajustes feitos garantem a não existência de estoques para setores em que isso não é comum, como os de serviço. Ao mesmo tempo, garantem que os estoques regionais não divirjam em grandes proporções dos estoques nacionais.

Assim, após a estimação das 27 Matrizes de Produção (setor x produto) para cada UF e da Matriz de Usos Regionais e Inter-regionais (produto x setor), finalmente a Matriz Inter-regional de Insumo-produto (setor x setor) poderá ser calculada.

Para isso, é necessária a construção, para cada uma das UFs (com $U F=$ $1, \ldots, 27)$, das matrizes de coeficientes de produção $\left(C P_{s \times p}^{U F}\right)$, as quais indicam a participação percentual de cada produto na produção de cada setor. Para isso, divide-se cada elemento das referidas matrizes regionais de produção pelo total de sua respectiva coluna, conforme a equação:

$$
C P_{s \times p}^{U F}=M P_{s \times p}^{U F} * i n v\left(\operatorname{diag}\left(\sum_{p=1}^{128} m p_{s p}^{U F}\right)\right)
$$

em que:

- $C P_{s \times p}^{U F}$ são os coeficientes de produção para as UFs;

- $M P_{s \times p}^{U F}$ são as Matrizes de Produção de cada UF;

- $m p_{s p}^{U F}$ refere-se à cada elemento $s p$ da Matriz de Produção em cada UF. 
Posteriormente, cria-se uma matriz bloco-diagonal composta de todas as 27 matrizes $C P_{s \times p}^{U F}$ construídas (setor x produto), com o número de colunas igual ao número de linhas da Matriz Inter-regional de Usos $(U)$ de cada UF (produto x setor) já estimadas, de modo que isso permite a seguinte pré-multiplicação.

$$
\left[\begin{array}{ccc}
C P_{s \times p}^{U F 1} & 0 & 0 \\
0 & \ddots & 0 \\
0 & 0 & C P_{s \times p}^{U F 27}
\end{array}\right] *\left[\begin{array}{ccc}
U_{p \times s}^{U F 1, U F 1} & \ldots & U_{p \times s}^{U F 1, U F 27} \\
\vdots & \ddots & \vdots \\
U_{p \times s}^{U F 27, U F 1} & \ldots & U_{p \times s}^{U F 27, U F 27}
\end{array}\right]=\left[\begin{array}{ccc}
Z_{s \times s}^{U F 1, U F 1} & \ldots & Z_{s \times s}^{U F 1, U F 27} \\
\vdots & \ddots & \vdots \\
Z_{s \times s}^{U F 27, U F 1} & \ldots & Z_{s \times s}^{U F 27, U F 27}
\end{array}\right]
$$

A matriz $Z$ resultante é a Matriz de CI (setor $\mathrm{x}$ setor). Os elementos da DF também podem ser multiplicados pela Matriz de coeficientes $C P_{s \times p}^{U F}$ para obter-se a DF (setor $\mathrm{x}$ setor).

Assim, utilizando o Consumo das Famílias como exemplo, segue-se:

$$
C F_{s \times 1}^{U F}=C P_{s \times p}^{U F} * C F_{p \times 1}^{U F}
$$

em que:

- $C F_{s \times 1}^{U F}$ é o Consumo das Famílias para uma determinada UF por setor $s$;

- $C F_{p \times 1}^{U F}$ é o Consumo das Famílias para a respectiva UF por produto $p$.

A mesma operação é feita para todos os outros elementos da DF já estimados por produto $p$.

\section{Análise sobre a estrutura produtiva do sistema estimado}

Para uma análise preliminar das relações interestaduais e da estrutura produtiva do sistema inter-regional estimado, a partir do método SUIT, inicialmente, serão comparados os fluxos de comércio estimados pelo SUIT para o ano de 2011 com os divulgados pelo CONFAZ. Em seguida, serão calculados os multiplicadores de produção totais e líquidos médios para cada UF. Posteriormente, será feita uma decomposição da produção por origem da DF.

Os dados do CONFAZ registram as transações comerciais entre os estados brasileiros e estão baseados na arrecadação do ICMS, de modo que tais informações estão desagregadas em 16 setores. No entanto, os dados estimados pelo método SUIT estão desagregados em 68 setores.

Diante desse impasse, foram comparados apenas os setores compatíveis às duas bases de dados, ficando excluídos, portanto, os dados dos setores da agricultura, indústria extrativa e serviços, que não estão disponíveis na base do CONFAZ. Isso implicou no fato de que os setores para os quais a referida comparação foi possível representaram $82 \%$ dos fluxos interestaduais do CONFAZ e $44,5 \%$ dos fluxos de comércio entre as UFs da matriz de insumo-produto estimada.

Para a construção dos dados referentes aos fluxos, somou-se cada valor de origem e destino, bem como de destino e origem. Por exemplo, no caso do fluxo de comércio entre o estado do Paraná e o estado de São Paulo, somou-se o fluxo do Paraná para São Paulo com o de São Paulo para o Paraná. 
A Tabela 1 apresenta a correspondência entre os setores da matriz de insumoproduto (estimados pelo método SUIT) e do CONFAZ.

Também calcularam-se os coeficientes de correlação de Pearson entre os fluxos de comércio interestaduais estimados pelo método SUIT e os divulgados pelo CONFAZ. De acordo com a Tabela 2, pode-se perceber que a correlação foi bastante elevada para todos os setores compatíveis, bem como para o total dos fluxos.

Tabela 1: Correspondência entre os setores da matriz de insumo-produto e do CONFAZ

\begin{tabular}{|c|c|}
\hline Setores CONFAZ & Setores da Matriz de Insumo-produto \\
\hline $\begin{array}{l}\text { Materiais } \\
\text { elétricos, som e } \\
\text { imagem }\end{array}$ & $\begin{array}{l}\text { Fabricação de equipamentos de informática, } \\
\text { produtos eletrônicos e ópticos } \\
\text { Fabricação de máquinas e equipamentos elétricos } \\
\text { Fabricação de máquinas e equipamentos mecânicos }\end{array}$ \\
\hline $\begin{array}{l}\text { Material de } \\
\text { transporte }\end{array}$ & $\begin{array}{l}\text { Fabricação de automóveis, caminhões e ônibus, } \\
\text { exceto peças } \\
\text { Fabricação de peças e acessórios para veículos } \\
\text { automotores } \\
\text { Fabricação de outros equipamentos de transporte, } \\
\text { exceto veículos automotores }\end{array}$ \\
\hline Indústria química & $\begin{array}{l}\text { Fabricação de químicos orgânicos e inorgânicos, } \\
\text { resinas e elastômeros } \\
\text { Fabricação de defensivos, desinfetantes, tintas e } \\
\text { químicos diversos } \\
\text { Fabricação de produtos de limpeza, cosméticos/ } \\
\text { perfumaria e higiene pessoal } \\
\text { Fabricação de produtos farmoquímicos e farmacêuticos }\end{array}$ \\
\hline $\begin{array}{l}\text { Produtos } \\
\text { minerais }\end{array}$ & $\begin{array}{l}\text { Refino de petróleo e coquerias } \\
\text { Fabricação de biocombustíveis }\end{array}$ \\
\hline Metais comuns & $\begin{array}{l}\text { Produção de ferro-gusa/ ferro ligas, siderurgia e } \\
\text { tubos de aço sem costura } \\
\text { Metalurgia de metais não ferrosos e a fundição de } \\
\text { metais } \\
\text { Fabricação de produtos de metal, exceto } \\
\text { máquinas e equipamentos }\end{array}$ \\
\hline $\begin{array}{l}\text { Alimentos, } \\
\text { bebidas e tabaco }\end{array}$ & $\begin{array}{l}\text { Fabricação e refino de açúcar } \\
\text { Outros produtos alimentares } \\
\text { Fabricação de bebidas } \\
\text { Fabricação de produtos do fumo }\end{array}$ \\
\hline $\begin{array}{l}\text { Materiais } \\
\text { plásticos e }\end{array}$ & $\begin{array}{l}\text { Fabricação de produtos de borracha e de material } \\
\text { plástico }\end{array}$ \\
\hline Porracha & $\begin{array}{l}\text { Fabricação de produtos têxteis } \\
\text { Confecção de artefatos do vestuário e acessórios }\end{array}$ \\
\hline $\begin{array}{l}\text { Peles, Couros, } \\
\text { Bolsas, Calçados e } \\
\text { Chapéus }\end{array}$ & Fabricaçã \\
\hline
\end{tabular}


Tabela 2: Correlação entre as participações (Origem/Destino): dados estimados pelo SUIT versus dados divulgados pelo CONFAZ

\begin{tabular}{lc}
\hline Setor & Correlação \\
\hline Máquinas e Materiais Elétricos & $95,26 \%$ \\
Material de Transporte & $86,81 \%$ \\
Indústria Química & $90,34 \%$ \\
Produtos Minerais & $82,21 \%$ \\
Metais Comuns & $89,81 \%$ \\
Alimentos, Bebidas e Tabaco & $90,27 \%$ \\
Plásticos, Borrachas e suas obras & $91,44 \%$ \\
Produtos Têxteis e suas obras & $76,22 \%$ \\
Peles, Couros, Bolsas e Chapéus & $86,19 \%$ \\
\hline TOTAL & $98,55 \%$ \\
\hline
\end{tabular}

A alta correlação entre os fluxos de comércio estimados pelo SUIT e os divulgados pelo CONFAZ, de forma agregada como aqui proposto, não garante a eficiência do método, já que os setores compatíveis entre o CONFAZ e o SUIT representam pouco mais de $40 \%$ dos fluxos que compõem o sistema inter-regional estimado.

No entanto, informações oficiais acerca dos fluxos de comércio interestadual são raras no Brasil, sendo o CONFAZ a única disponível, por isso, a alta correlação entre as duas bases de dados, apesar de não validar os resultados do modelo, sugere que, os fluxos estimados pelo SUIT e os dados divulgados pelo CONFAZ têm um comportamento bastante similar nos setores compatíveis.

\subsection{Multiplicadores de produção}

Os multiplicadores de produção revelam os impactos diretos e indiretos na produção necessários para atender a variação em uma unidade monetária na DF de cada setor em cada UF. Para o cálculo dos referidos multiplicadores, é necessária a construção da matriz inversa de Leontief.

Considerando os fluxos intersetoriais e inter-regionais para duas regiões hipotéticas $L$ e $M$, com dois setores $i$ e $j$, respectivamente, tem-se:

- $Z_{i j}^{L L}$ - fluxo monetário do setor $i$ para o setor $j$ da região $L$;

- $Z_{i j}^{M L}$ - fluxo monetário do setor $i$ da região $M$, para o setor $j$ da região $L$.

Definidos os fluxos monetários, é possível montar a matriz $Z$ :

$$
Z=\left[\begin{array}{cc}
Z^{L L} & Z^{L M} \\
Z^{M L} & Z^{M M}
\end{array}\right]
$$

em que:

- $Z^{L L}$ e $Z^{M M}$ são os fluxos monetários intrarregionais;

- $Z^{L M}$ e $Z^{M L}$ são os fluxos monetários inter-regionais. 
Considerando as definições da Equação (23), o modelo inter-regional de insumo-produto pode ser escrito como:

$$
X_{i}^{L}=z_{i i}^{L L}+z_{i j}^{L L}+z_{i i}^{L M}+z_{i j}^{L M}+Y_{i}^{L}
$$

em que:

- $X_{i}^{L}$ é o total produzido do setor $i$ na região $L$;

- $Y_{i}^{L}$ é a DF total do setor $i$ na região $L$, onde:

- $Y_{i}^{L}=Y_{i}^{L L}+Y_{i}^{L M}$

- $Y_{i}^{L L}$ e $Y_{i}^{L M}$ são respectivamente as demandas intra e inter-regionais do setor i. cial:

Os coeficientes técnicos de produção podem ser definidos na forma matri-

$$
A^{L L}=Z^{L L}\left(\hat{X}^{L}\right)^{-1}
$$

Da mesma forma, podem-se estimar: $A^{M M}, A^{L M}, A^{M L}$. A partir disso, temse que no sistema nacional de insumo-produto:

$$
\begin{gathered}
(I-A) X=Y \\
X=(I-A)^{-1} Y=B Y
\end{gathered}
$$

em que:

- Y refere-se à DF;

- $B$ diz respeito à inversa de Leontief.

Diante do exposto, o modelo convencional de insumo-produto, descrito pelas Equações (26) e (27), pode ser utilizado em um sistema inter-regional conforme apresentado a seguir.

$$
X=\left[\begin{array}{c}
X^{L} \\
\vdots \\
X^{M}
\end{array}\right] ; A=\left[\begin{array}{cc}
A^{L L} & A^{L M} \\
A^{M L} & A^{M M}
\end{array}\right] ; Y=\left[\begin{array}{c}
Y^{L} \\
\vdots \\
Y^{M}
\end{array}\right]
$$

O efeito multiplicador da produção é, então, obtido pelas colunas da matriz inversa de Leontief. A Tabela 3 apresenta, para as 27 UFs, a média percentual da produção necessária para atender uma variação na DF, identificando a parte da produção que permanece na região (efeito intrarregional) e a parcela que transborda para as demais regiões do sistema (efeito inter-regional). Além disso, essa análise dos multiplicadores pode ajudar a compreender o grau de autossuficiência de cada UF. 
Tabela 3: Multiplicador de Produção Total e Líquido, média percentual por Unidade da Federação para as 27 UFs no ano de 2011

\begin{tabular}{|c|c|c|c|c|}
\hline \multirow{2}{*}{ UF } & \multicolumn{2}{|c|}{ TOTAL } & \multicolumn{2}{|c|}{ LÍQUIDO } \\
\hline & INTRA & INTER & INTRA & INTER \\
\hline $\mathrm{RO}$ & $71 \%$ & $29 \%$ & $31 \%$ & $69 \%$ \\
\hline $\mathrm{AC}$ & $74 \%$ & $26 \%$ & $30 \%$ & $70 \%$ \\
\hline $\mathrm{AM}$ & $75 \%$ & $25 \%$ & $37 \%$ & $63 \%$ \\
\hline RR & $75 \%$ & $25 \%$ & $27 \%$ & $73 \%$ \\
\hline PA & $73 \%$ & $27 \%$ & $36 \%$ & $64 \%$ \\
\hline AP & $71 \%$ & $29 \%$ & $26 \%$ & $74 \%$ \\
\hline TO & $70 \%$ & $30 \%$ & $29 \%$ & $71 \%$ \\
\hline MA & $77 \%$ & $23 \%$ & $36 \%$ & $64 \%$ \\
\hline PI & $72 \%$ & $28 \%$ & $31 \%$ & $69 \%$ \\
\hline CE & $79 \%$ & $21 \%$ & $48 \%$ & $52 \%$ \\
\hline RN & $75 \%$ & $25 \%$ & $41 \%$ & $59 \%$ \\
\hline PB & $73 \%$ & $27 \%$ & $32 \%$ & $68 \%$ \\
\hline PE & $81 \%$ & $19 \%$ & $48 \%$ & $52 \%$ \\
\hline $\mathrm{AL}$ & $76 \%$ & $24 \%$ & $38 \%$ & $62 \%$ \\
\hline SE & $74 \%$ & $26 \%$ & $39 \%$ & $61 \%$ \\
\hline BA & $78 \%$ & $22 \%$ & $50 \%$ & $50 \%$ \\
\hline MG & $78 \%$ & $22 \%$ & $50 \%$ & $50 \%$ \\
\hline ES & $81 \%$ & $19 \%$ & $42 \%$ & $58 \%$ \\
\hline RJ & $85 \%$ & $15 \%$ & $63 \%$ & $37 \%$ \\
\hline SP & $88 \%$ & $12 \%$ & $72 \%$ & $28 \%$ \\
\hline PR & $78 \%$ & $22 \%$ & $49 \%$ & $51 \%$ \\
\hline SC & $80 \%$ & $20 \%$ & $45 \%$ & $55 \%$ \\
\hline RS & $79 \%$ & $21 \%$ & $53 \%$ & $47 \%$ \\
\hline MS & $75 \%$ & $25 \%$ & $39 \%$ & $61 \%$ \\
\hline MT & $72 \%$ & $28 \%$ & $38 \%$ & $62 \%$ \\
\hline $\mathrm{GO}$ & $75 \%$ & $25 \%$ & $39 \%$ & $61 \%$ \\
\hline DF & $77 \%$ & $23 \%$ & $41 \%$ & $59 \%$ \\
\hline
\end{tabular}

Fonte: elaborado pelos autores.

O multiplicador de produção total considera o impacto na produção provocado pela variação na $\mathrm{DF}$, considerando a injeção inicial de uma unidade monetária. Já o multiplicador de produção líquido diz respeito ao efeito multiplicador descontado da injeção inicial.

De acordo com a Tabela 3, pode-se identificar que São Paulo e Rio de Janeiro foram os estados mais autossuficientes do Brasil em 2011, com respectivamente $88 \%$ e $85 \%$ do efeito multiplicador da produção total e $72 \%$ e $63 \%$ do efeito líquido, permanecendo dentro dos respectivos estados. Já os estados de Tocantins e Roraima são os que apresentam os níveis de autossuficiência mais baixos.

Por sua vez, os estados de São Paulo e Rio de Janeiro, juntos, representaram para o ano de 2012 mais de $42 \%$ do PIB brasileiro ${ }^{20}$. Além disso, os respectivos estados possuem grande diversidade industrial e de serviços. Essas características fazem com que grande parte do efeito multiplicador se man-

\footnotetext{
${ }^{20}$ Dados do IBGE disponíveis em http : / / www . ibge .gov.br/estadosat /
} 
tenha dentro dessas regiões, já que a diversidade e a grande quantidade de insumos à disposição dos agentes internamente permitem que eles adquiram suas matérias-primas de indústrias locais.

No que diz respeito aos estados de Roraima e Tocantins, juntos eles são responsáveis por menos de $1 \%$ do PIB nacional. Sua base econômica concentrada em produtos primários, tais como bens agrícolas e minério, faz com que o efeito multiplicador da produção transborde para as outras regiões do país.

Com relação às grandes regiões brasileiras, chama-se a atenção para o fato de que a região Sudeste mostrou-se relativamente mais autossuficiente quando comparada às regiões Norte e Nordeste, do ponto de vista do multiplicador de produção, mostrando que as duas últimas apresentaram uma estrutura produtiva mais voltada para atender a demanda das demais regiões.

Diante disso, é importante destacar que as informações apresentadas corroboram com as disponíveis na literatura (Sesso Filho et al. 2006), indicando, portanto, consistência dos resultados.

\subsection{Decomposição da produção de acordo com a origem da Demanda Final}

A análise da decomposição regional da produção doméstica no que diz respeito à origem da DF complementa a análise dos multiplicadores de produção. De acordo com Haddad et al. (2016), a decomposição regional da produção, considerando a origem regional da demanda, leva em conta não apenas a estrutura dos multiplicadores, mas também a estrutura da DF do sistema estimado.

Dada a seguinte estrutura do sistema inter-regional de insumo-produto:

$$
\begin{aligned}
& X^{1}=B^{11} Y^{1}+\ldots+B^{1 R} Y^{R} \\
& \begin{array}{cccc}
\vdots & \vdots & & \vdots \\
X^{R} & = & B^{R 1} Y^{1} & +\ldots+ \\
B^{R R} Y^{R}
\end{array}
\end{aligned}
$$

Considerando que a DF $(Y)$ inclui demandas domésticas $(v)$ e do exterior (e), pode-se reescrever a Equação 29 da seguinte maneira:

$$
\begin{array}{cccc}
X^{1}= & B^{11}\left(v^{11}+\ldots+v^{U F 1}+e^{1}\right) & +\ldots+ & B^{1 U F}\left(v^{1 U F}+\ldots+v^{U F U F}+e^{U F}\right) \\
\vdots & \vdots & & \vdots \\
X^{U F}= & B^{U F 1}\left(v^{11}+\ldots+v^{U F 1}+e^{1}\right) & +\ldots+ & B^{U F U F}\left(v^{1 U F}+\ldots+v^{U F U F}+e^{U F}\right)
\end{array}
$$

Dessa forma, pode-se calcular a proporção da produção de cada UF que está vinculada à demanda gerada por ela mesma, por cada uma das outras UFs e pelo exterior.

A Tabela 4 apresenta a decomposição da produção de cada estado de acordo com a demanda das 27 UFs brasileiras e do Restante do Mundo (RM). Essa análise permite identificar o quanto da produção de cada UF é gerada para atender a DF interna e o quanto é gerada para atender a demanda das outras UFs e do RM.

Conforme a Tabela 4, os estados brasileiros que possuem a maior parte de sua produção vinculada à DF interna são Roraima e Acre, com respectivamente $82,3 \%$ e $73,9 \%$ de sua produção vinculada à sua própria DF. Isso ocorre, em parte, pelo fato dos referidos estados estarem distantes dos grandes centros produtivos do país na Região Sudeste, o que dificulta o comércio de bens 
Tabela 4: Decomposição da produção regional baseada na origem da Demanda Final para as 27 UFs no ano de 2011 $(\mathrm{em} \%)$

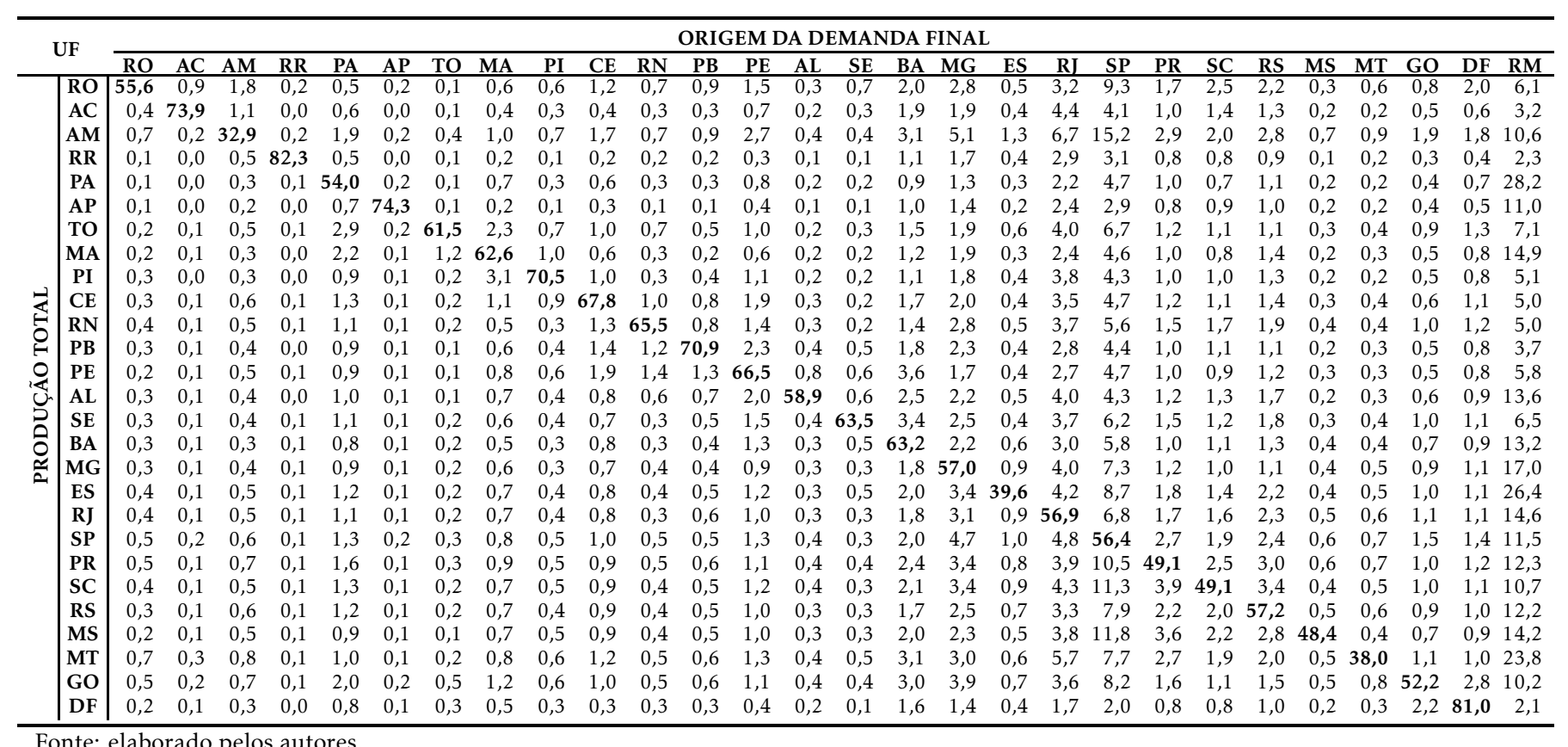


com menor valor agregado. Isso ocorre também pelos referidos estados apresentarem um parque industrial ainda em formação, voltado principalmente ao abastecimento interno.

Já os estados com menor percentual da produção vinculado à própria DF são Amazonas (32,9\%), Mato Grosso (38\%) e Espírito Santo (39,6\%). No que tange ao estado do Amazonas, pode-se inferir que o alto percentual de produção vinculado à DF de outros estados ocorre principalmente devido à Zona Franca de Manaus e à indústria petroquímica. Com relação ao Mato Grosso, a produção agropecuária para exportação é o principal responsável por esse resultado.

No Espírito Santo, o alto percentual da produção vinculado à DF de outros estados ocorre, em grande parte, devido à indústria de petróleo, minérios e celulose. Além disso, o estado também possui uma intensa atividade portuária, que também o faz apresentar o segundo maior percentual da produção ligada à exportação para o restante do mundo, entre todos os estados brasileiros.

\section{Conclusão}

O presente artigo teve como objetivo apresentar de forma detalhada o método SUIT, utilizado na construção de um sistema inter-regional de insumoproduto para as 27 UFs brasileiras. Também foi feita uma análise preliminar das relações interestaduais e da estrutura produtiva brasileira de acordo com as informações estimadas por esse método.

Constatou-se que o SUIT pode ser aplicado na construção de sistemas interregionais de insumo-produto para qualquer país que publique as suas Tabelas de Usos e Recursos nacionais e que disponha de algumas informações subnacionais para serem utilizadas no processo de regionalização. Além disso, suas principais características são a consistência do sistema inter-regional estimado com a matriz de insumo-produto nacional e com as contas regionais.

O SUIT pode ser aplicado para qualquer nível de regionalização, seja para um sistema inter-regional entre UFs, como exemplificado no texto, entre municípios de uma UF ou entre municípios de um país. Também apresenta a vantagem de poder ser diretamente aplicado na construção sistemas compostos por diferentes hierarquias regionais, por exemplo, que contenham um município, o restante da UF em que ele está contido e o restante do país onde a UF está contida.

As altas correlações obtidas entre os fluxos de comércio estimados pelo SUIT e os divulgados pelo CONFAZ, bem como a corroboração dos resultados obtidos na análise acerca da estrutura produtiva do sistema estimado com as informações disponíveis na literatura permitem concluir que o método SUIT capta de forma consistente as peculiaridades regionais presentes no comércio interestadual do país. Desse modo, a metodologia proposta mostra-se adequada ao estudo da interdependência econômica regional, ainda que desenvolvida em um ambiente com informação limitada.

Algumas possíveis sugestões para o aprimoramento do SUIT seriam: (i) o valor inicial na estimação dos fluxos intrarregionais é baseado no CIQ. Este coeficiente, segundo Flegg et al. (2016) e Lamonica \& Chelli (2018), não apresenta uma bom desempenho quando comparado a outras variações de coeficientes locacionais. Por isso, a utilização do Coeficiente Locacional Simples ou o Coeficiente Locacional de Flegg, poderia dar resultados iniciais melho- 
res; (ii) no que diz respeito aos fluxos intrarregionais, a regra de decisão dos coeficientes técnicos que utiliza um X diferente para cada setor, baseada em seu potencial de comércio, não tem uma fórmula de cálculo, sendo apenas determinada de maneira ad hoc. A determinação do valor do X através de um cálculo estatístico daria mais legitimidade a ele.

\section{Agradecimentos}

Os autores gostariam de agradecer os comentários recebidos dos pareceristas anônimos e dos editores de Economia Aplicada, que contribuíram para uma melhoria na qualidade do artigo, tornando-o mais claro e consistente.

\section{Referências Bibliográficas}

Barros, G. \& Guilhoto, J. J. M. (2014), 'The Regional Economic Structure of Brazil in 1959: An Overview Based on an Interstate Input-Output Matrix', Revista Brasileira de Economia 68(3), 317-335.

Carvalho, T. S. \& Perobelli, F. S. (2009), 'Avaliação da intensidade de emissões de CO2 setoriais e na estrutura de exportações: um modelo inter-regional de insumo-produto São Paulo/restante do Brasil', Economia Aplicada 13(1), 99124.

Dixon, P. B. \& Rimmer, M. T. (2004), Disaggregation of results from a detailed general equilibrium model of the US to the State level.

URL: https://www.copsmodels.com/regional/dixpap.pdf

Domingues, E. P. \& Haddad, E. A. (2002), Matriz Inter-regional de Insumoproduto Minas Gerais/Resto do Brasil: Estimação e Extensão para Exportações, in 'Anais do X Seminário sobre a Economia Mineira', Diamantina.

Faria, W. R. \& Haddad, E. A. (2014), 'Estimação das elasticidades de substituição do comércio regional do Brasil', Nova Economia 24(1), 141-168.

Flegg, A. T., Mastronardi, L. J. \& Romero, C. A. (2016), 'Evaluating the FLQ and AFLQ formulae for estimating regional input coefficients: empirical evidence for the province of Córdoba, Argentina', Economic Systems Research 28(1), 21-37.

Freitas, F. (2016), 'Matriz de Capital'.

URL: http://www.projetopib.org/?p=documentos

Gonçalves Jr, C. A. \& Guilhoto, J. J. M. (2018), Estimation of Interregional Systems, is the Method Important? Comparing Brazil's SUIT and IIOAS Approaches, in '26th International Input-Output Conference', Juiz de Fora, Brazil.

Guilhoto, J. J. M., Azzoni, C. R., Ichihara, S. M., Kadota, D. \& Haddad, E. A. (2010), Matriz de Insumo-Produto do Nordeste e Estados: Metodologia e Resultados, Fortaleza: Banco do Nordeste do Brasil.

Guilhoto, J. J. M. \& Sesso-Filho, U. A. (2005a), 'Análise da estrutura produtiva da Amazônia brasileira', Amazônia Ciência e Desenvolvimento 1(1), 7-33. 
Guilhoto, J. J. M. \& Sesso-Filho, U. A. (2005b), 'Estimação da Matriz InsumoProduto a Partir de Dados Preliminares das Contas Nacionais', Economia Aplicada 9(2), 277-299.

Guilhoto, J. J. M. \& Sesso-Filho, U. A. (2010), 'Estimação da matriz insumoproduto utilizando dados preliminares das contas nacionais : aplicação e análise de indicadores econômicos para o Brasil em 2005', Economia E Tecnologia 23, 53-62.

Haddad, E. A. (2009), Interregional Computable General Equilibrium Models, in M. Sonis \& G. J. D. Hewings, eds, 'Tool Kits in Regional Science: Theory, Models and Estimation', Berlin: Springer.

Haddad, E. A., Faria, W. R., Galvis-Aponte, L. A. \& Hahn-De-Castro, L. W. (2016), Interregional Input-Output Matrix for Colombia, 2012.

Haddad, E. A., Gonçalves Jr, C. A. \& Nascimento, T. O. (2017), 'Matriz interestadual de insumo-produto para o Brasil: uma aplicação do método IIOAS', Revista Brasileira de Estudos Regionais e Urbanos 11(4), 424-446.

Hirschman, A. (1977), Transmissão inter-regional e internacional do crescimento econômico, in J. Schwartzman, ed., 'Economia regional: textos escolhidos', CEDEPLAR, Belo Horizonte, pp. 35-52.

Ichihara, S. M., Guilhoto, J. \& Imori, D. (2008), Geoprocessing and Estimation of Interregional Input-Output Systems an Application to the State of Sao Paulo in Brazil, in 'Proceedings of the 48th Congress of the European Regional Science Association', Liverpool, pp. 1-45.

URL: https://papers.ssrn.com/sol3/papers.cfm?abstract_id=2407573

Isard, W. (1951), 'Interregional and Regional Input-Output Analysis : A Model of a Space-Economy', The Review of Economics and Statistics 33(4), 318328 .

Isard, W., Azis, I. J., Drennan, M. P., Miller, R. E., Saltzman, S. \& Thorbecke, E. (1998), Methods of Regional and Inter-regional Analysis, Aldershot: Ashgate, Aldershot.

Kaplan, A. (1969), A conduta na pesquisa: metodologia para as ciências do comportamento, São Paulo.

Lakatos, E. M. \& Marconi, M. A. (2011), Metodologia científica, 6a edn, São Paulo: Atlas.

Lamonica, G. R. \& Chelli, F. M. (2018), 'The performance of non-survey techniques for constructing sub-territorial input-output tables', Papers in Regional Science 97(4), 1169-1202.

Leontief, W. (1986), Input-Output Economics, 2nd edn, New York: Oxford University Press.

Leontief, W., Hollis, B., Chenery, P., Clark, P., Duesenberry, J., Ferguson, A., Grosse, R., Hlzman, M., Isard, W. \& Kistin, H. (1953), Studies in the Structure of the American Economy, White Plains, NY: International Arts and Science Press. 
McDougall, R. (1999), Entropy Theory and RAS are Friends, GTAP Working Paper 06, Global Trade Analysis Project (GTAP), Department of Agricultural Economics, West Lafayette, IN: Purdue University.

URL: www.gtap.agecon.purdue.edu/resources/res_display.asp?RecordID $=300$

Miller, R. E. \& Blair, P. (2009), Input-output analysis: foundations and extensions, 2 edn, Cambridge University Press.

Mínguez, R., Oosterhaven, J. \& Escobedo, F. (2009), 'Cell-corrected RAS method (CRAS) for updating or regionalizing an input-output matrix', Journal of Regional Science 49(2), 329-348.

Montoya, M. A. (1999), Análise insumo-produto internacional no Mercosul: desenvolvimento econômico regional e interdependência estrutural., 1 edn, Passo Fundo: ediupf.

Perobelli, F. S., Mattos, R. S. \& Faria, W. R. (2007), 'Interações energéticas entre o estado de Minas Gerais e o restante do Brasil: uma análise inter-regional de insumo-produto', Economia Aplicada 11(1), 113-130.

Porsse, A. A., Haddad, E. A. \& Pontual, E. (2003), Estimando uma Matriz de Insumo-Produto Inter-regional Rio Grande do Sul-Restante do Brasil, in 'VI Encontro de Economia Região Sul', Curitiba.

Riddington, G., Gibson, H. \& Anderson, J. (2006), 'Comparison of gravity model, survey and location quotient-based local area tables and multipliers', Regional Studies 40(9), 1069-1081.

Round, J. I. (1983), 'Nonsurvey Techniques: A Critical Review of the Theory and the Evidence', International Regional Science Review 8(3), 189-212.

Roy, J. R. \& Thill, J. C. (2004), 'Spatial interaction modelling', Papers in Regional Science 83(1), 339-361.

Sanén, N. E. A. \& Gamboa, J. M. S. (2016), 'Metodological proposal for the construction of a regional input-output matrix using a bottom-up approach and its statistical assessment', Investigación Económica LXXV(298), 3-56.

Sargento, A. L. M. (2009), Regional input-output tables and models: interregional trade estimation and input-output modeling based on total use rectangular tables, Phd dissertation in economics, University of Coimbra.

Sesso Filho, U. A., Moretto, A. C., Rodrigues, R. L. \& Guilhoto, J. J. M. (2006), 'Interações sinérgicas e transbordamento do efeito multiplicador de produção das grandes regiões do Brasil', Economia Aplicada 10(2), 225-247.

Többen, J. \& Kronenberg, T. H. (2015), 'Construction of multi-regional input-output tables using the charm method', Economic Systems Research 27(4), 487-507. 
